\title{
Problems Faced by Green Towns Based on the Rural Revitalization Strategy: Taking Qiaoshi Town as an Example
}

\author{
Xianze PENG ${ }^{\mathrm{a}, \mathrm{b}}$, Meihan FENG ${ }^{\mathrm{b}, 1}$ and Juan LIN ${ }^{\mathrm{a}, \mathrm{b}}$ \\ ${ }^{a}$ College of Marxism, Wuchang University of Technology, Wuhan 430200, Hubei, \\ China \\ ${ }^{\mathrm{b}}$ College of Marxism, Hubei University of Technology, Wuhan 430070, Hubei, China
}

\begin{abstract}
The rural revitalization strategy is the main strategy proposed by the 19th National Congress of the Communist Party of China. The Central Rural Work Conference held at the end of 2020 emphasized that after the comprehensive victory in the fight against poverty, the focus of China's work on the "three rural areas" had shifted historically, i.e., to comprehensively promote Rural revitalisation. The study of the comprehensive promotion of rural revitalization in the new development stage is of great theoretical value and practical significance to the comprehensive construction of a modern socialist country. The state has put forward new requirements of revitalization and construction of rural areas from top to bottom. This article briefly analyzes the problems faced by rural revival based on the perspective of ecological civilization. It takes Qiaoshi Town as an example to explain the main methods of promoting rural regeneration from the perspective of ecological civilization. I hope this article's research content can bring certain value and enlightenment to the activation of rural ecosystems in various places.
\end{abstract}

Keywords. Rural revitalization, green ecology, urban development

\section{Introduction}

A village is a regional which includes multiplication characteristics in natural, social, and economic [1]. It has multiple functions such as production, life, ecology, and culture. It is necessary to promote mutualistic development, co-exist with cities and towns and establish the main space for human activities. Implement the "three-step" strategy of rural revitalization and realize the integrated development of urban and rural areas. Urban construction is an important tool for implementing the rural revitalization strategy, and has an irreplaceable position and role in the implementation of the new urbanization and rural revitalization strategies. To comprehensively promote rural revitalization is a comprehensive revitalization involving rural economy, politics, culture, society, ecology and other aspects, not a revitalization that only attaches importance to the material development of the countryside while ignoring the spiritual emptiness of the countryside, nor a revitalization that only thinks about the economic development of the countryside while ignoring the destruction of the rural environment, as General Secretary Xi Jinping

1 Corresponding Author, Meihan FENG, College of Marxism, Hubei University of Technology, Wuhan 430070, Hubei, China; Email: 786317698@qq.com. 
pointed out, "the depth, breadth and difficulty of comprehensively promoting rural revitalization It is no less difficult than the fight against poverty" [2]. For this reason, we must continue to carry forward the great spirit of poverty eradication, find the right way and method to promote rural revitalisation, and take targeted and effective measures to promote rural revitalisation and achieve ecologically sound development.

In the 21st century, under the background of the comprehensive strategy has implemented in Chinese rural revitalization, the development of green towns in Qiaoshi Town requires reform and innovation and then explores the new models for green town development in the new generation.

\section{A Brief Introduction to the Concept of Rural Revitalization}

A country will prosper if its rural is prosperous, and the Country will decline if the rural is declining. The Chinese people's demand for a better life is constantly increasing, and the contradiction between uneven and inadequate development is the most prominent problem in rural areas. Our country is still in the first stage of socialism, and such characteristics will be reflected in the localities for a long time. When we want to build a well-off society in the all-around way and build a modern and powerful socialist country in a comprehensive way, the most arduous and difficult work is lying in the countryside. The most extensive and deepest foundation lies in the countryside, so the greatest potential and endurance lies in the countryside. By the overall requirements of industrial prosperity, ecological livability, rural civilization, effective governance, and affluent life, we will prioritize the development of agriculture with rural areas and establish and improve an integrated urban-rural development system and policy system so that to adjust to the promoting of rural economic construction, political construction, and cultural construction. The modernization of social structure, ecological civilization construction, party building, rural governance system, and governance capabilities accelerate the modernization of agriculture and rural areas, the path to the activation of socialist rural areas with Chinese characteristics, and sustainable agriculture with potential industries. All above making agriculture a promising sector and making farmers attractive. The following will take the town of Qiaoshi as an example for some discussions.

\section{The Rural Characteristics of Qiaoshi Town and the Problems Faced by Rural Revitalization}

Qiaoshi Town is located at the southern end of Jianghan Plain which coveres an area of 150 square kilometers and has the jurisdiction over 15 administrative villages and six farms. The land is flat, and the rivers intersect with the ports. Qiaoshi town faces the largest freshwater lake in its province named Honghu in the east, the Golden Waterway Yangtze River in the south, and meets the open city Yueyang across the river. Qiaoshi town is rich in aquatic resources, and the pillar industries of this town are fishery and aquaculture. There are many problems in rural revitalization at this stage, including rural planning, green development, and rural agriculture and industrial development. This article will take Qiaoshi town as an example to discuss the problems faced by green towns under rural revitalization strategy. 


\subsection{Rural Planning Issues}

The scientific nature of the overall rural planning has always been valued, and the construction of green rural areas also needs planning work. However, combining with the actual investigation of Qiaoshi town, it can be found that although the specific deployment arrangements are continuously implemented, in the design and implementation of rural planning, the phenomenon of lack of scientificity in rural planning is quite common, and also there is a lack of coordination among various plans. Nature makes it difficult to implement the plan. Besides, due to the planning changes frequently, sustainable rural planning which is difficult to promote will also restrict the green development of cities and towns, so to the negative impact of agrarian ecological civilization's revitalization must be paid attention [3].

\subsection{Green Development Path Issues}

In the past few years, the party and government have repeatedly emphasized the implementation direction of the construction of rural ecological civilization and proposed a civilized agricultural model, green water and green mountains, golden mountains, and silver mountains. In the concept of green development, the participation mechanism of villagers is not perfect. The authorities and responsibilities of various departments are not clear, and coordination and coordination are not uncommon. In green development, the participation of villagers has also limited rural development to a certain extent which is causing many problems.

\subsection{Rural Agriculture and Industrial Development Issues}

In the context of green development, the problem between industrial development and agricultural development in rural revitalization cannot be ignored either. As the foundation and key to rural revitalization, its impact on the economy and industry is extremely far-reaching. When we talk about the survey of Qiaoshi Town, it can be found that the problems of high pollution and low output are common in rural agriculture. The types of agricultural products are single while the quality is not high. In the rural industry, the phenomena of weak environmental awareness, backward production technology, and small industrial scale are very common, and the ecological and environmental problems caused by these phenomena also need to be paid attention [4].

\section{The Choice of Ways to Promote Rural Revitalization from the Perspective of Ecological Civilization}

In green development, based on the problems faced in rural areas, the promotion of rural revitalization, the merger of rural green development plans, the green development of the merger mechanism innovation, and the development of green industry development include mergers.

\subsection{Integrating Green Development into Rural Planning}

To solve rural planning and ensure that rural revitalization adapts to the background of 
green growth better, we must strive to integrate green development into rural planning to achieve green urban construction. This integration can strengthen rural planning coordination which will ensure the continuity and authority of rural planning. To enhance rural planning coordination, rural planning must focus on strategic thinking and systematic thinking and coordinate the policies, measures, tasks, indicators, goals, and content of planning at all levels and aspects while avoiding quarrels and conflicts. For example, environmental planning, urban planning, industrial layout, urban construction, environmental management and urban management should be promoted simultaneously. Overall planning for agricultural production, life, and ecological development should be done at the same time. Highlighting the feasibility and differences of rural planning, step by step, optimization of specific measures and integration of local characteristics are the keys to success. With the development of industrial planning, it is also necessary to pay attention to the protection of ecology and the human environment. Because our streets have been extensively managed before and the economy has been greatly improved, but the ecological environment has been destroyed. At that time, we should not make the same mistake again. Also, we must plan the countryside, integrate the countryside and the natural environment, create a natural and green living space rationally for the villagers. Each village has its humanitarian environment and we need to protect all of them. This improves our characteristics and serves as an important publicity point for the development of tourism and other industries.

\subsection{Integrating Green Development into Industrial Development}

To truly integrate green development into industrial development, we can start with the transformation and upgrading of traditional industries and exploring the Internet. The transformation and upgrading of traditional enterprises need to focus on agriculture and industry separately. Also the integration and exploration of "ecology + Internet" cannot be ignored. The transformation and upgrading of agriculture must target ecological agriculture and agricultural product processing industries. For example, the pillar industry of Qiaoshi Town is fishery. The development of the aquatic product processing industry, branding strategy, scale and standardization focus on the ecological fishery industry chain, expanding green, high-quality marine products and the construction of related enterprises and bases, improving the quality of agricultural products and ensuring Prices need to improve the quality of farm products. To increase the price of agricultural products, strengthen the establishment of geographical indications of agricultural products, the environmental protection and management of production areas, to enhance agricultural land and improve the ecological environment in rural areas, we must also pay attention to it. Exploring the combination of "ecology + Internet", focusing on the development of ecological agriculture, ecological tourism, tourism experience, sports and leisure industries, and directly transform the beautiful ecological environment into economic benefits. The exploration of the Internet helps to "globalize" local products. Besides, in terms of local activation and the benefits of product production, the positive role which the Internet can play is also worth noting. We should make full use of new media platforms such as Weibo, WeChat official account, and short video to connect the green mountains and the golden mountains and silver mountains and open up channels to communicate with the outside world. The status quo of information asymmetry between urban and rural areas and information occlusion in rural areas may change. The Internet also helps villagers more easily obtain information about urban labor, agricultural product markets, agricultural products, agricultural technology and 
"agriculture, rural areas and farmers" policies. The Internet can also provide rural tourism project promotion and agricultural product promotion based on new media platforms and support two-way communication process [5].

\section{A Practical Path for the Construction of Rural Ecological Civilization}

Strengthen the construction of rural ecological civilization, is an important part of the vigorous implementation of rural construction action, is an important part of the realization of green town development; based on the research practice of the town of Qiaoshi, promote the construction of rural ecological civilization, specifically from five aspects of efforts. The first is to change the rural way of life. Rural lifestyles should adhere to the theme of changing traditional patterns, i.e., reducing the burning of firewood for cooking in indiscriminate forestry, and vigorously promoting the use of electricity for cooking and heating [6]. It is also necessary to prohibit the burning of wild fires, straw and straw, and other undesirable practices that seriously pollute the air, and to increase the penalties for them in accordance with the law. Second, change the way of production in rural areas. Rural production methods should adhere to the concept of green development as a guide, that is, in grasping the intersection of water for farming and water for breeding to improve the utilization rate of water resources and realize the recycling and full use of water resources; in continuously reducing the use of chemical fertilizers and pesticides to vigorously promote the green transformation of agricultural production; in improving machinery and equipment and adopting advanced technology to promote low consumption and high utilization of water in the agricultural products processing industry. Third, build sewage treatment facilities. Rural sewage discharge has the characteristics of non-concentration, indiscriminate discharge, i.e., the situation of farmers living in scattered areas leads to the non-concentration of sewage discharge, and the situation of farmers living along rivers leads to the local nature of sewage discharge. Therefore, the need to build rural sewage treatment facilities to reduce the degree of damage and impact of domestic sewage, agricultural sewage. Fourth, increase the treatment of domestic waste. Dealing with domestic waste is an inherent requirement for building beautiful villages, and it is necessary to "promote source classification and reduction, resource-based treatment and utilization, and build a number of comprehensive organic waste disposal and utilization facilities" [7]. Five is to carry out village greening action. The main measures are: to carry out environmental protection publicity and education to enhance farmers' awareness of environmental protection; to increase the efforts to put rubbish ponds and bins, and to change farmers' habits of littering along river slopes and roadsides; to carry out tree planting and flower planting activities, and to carry out gardening and greening maintenance to improve village air quality in the beautification of village appearance.

\section{References}

[1] Proposals of the Central Committee of the Communist Party of China on formulating the Fourteenth Five-Year Plan for national economic and social development and the long-term goals for 2035 People's Daily 2020-11-04.

[2] Xi Jinping stressed during an inspection tour in Guangxi to liberalize thinking, deepen reform and concentrate on taking up practical work to build a magnificent Guangxi of socialism with Chinese characteristics in the new era People's Daily 2021-04-28. 
[3] Zhang Y L, Wang G M and Liu L B 2020 Theoretical explanation, contradiction analysis, and breakthrough path of my country's rural revitalization strategy Journal of Tianjin Normal University (Social Science Edition) 3 52-61.

[4] Yang X N 2020 The development path of new ecological farms in my country under the background of ecological liveability Agricultural Economics 4 31-33.

[5] Chen A J and Yan C H 2020 From ecological poverty to green well-off-the road to rural revitalization in ecologically fragile areas Yunnan Social Sciences $124-31$.

[6] Opinions of the Central Committee of the Communist Party of China and the State Council on comprehensively promoting rural revitalization and accelerating agricultural and rural modernization People's Daily 2021-02-22.

[7] Jiang Y M and Xie Q 2021 Solid promotion of common prosperity: Logical reasoning and realization path Economic Journal (04) 15-24+2. 